\title{
Horizontal and vertical variations in survival rates of juvenile bivalves, Anadara kagoshimensis (Tokunaga, 1906), Ruditapes philippinarum (Adams \& Reeve, 1850) and Atrina sp., experimentally caged in the inner area of the Sea of Ariake, Japan
}

\author{
Takeo Kurihara - Kazumasa Hashimoto - Shoji Nakano • \\ Yukihiko Matsuyama - Atsushi Ito - Masaei Kanematsu • \\ Kazumaro Okamura
}

Received: 27 July 2018/Accepted: 25 November 2018/Published online: 29 November 2018 (C) The Author(s) 2018

\begin{abstract}
In the inner area of the Sea of Ariake, rearing experiments were conducted to examine how the survival rates of juveniles of three bivalve species (Anadara kagoshimensis, Ruditapes philippinarum, Atrina sp.) vary among sea areas and heights above the seabed. In three runs of the experiment, replicate samples of the three bivalves were kept in trays set at various heights above the seabed (range $0-40 \mathrm{~cm}$ ) at one to six stations for 15-16 days. Results were as follows. (1) Survival rates varied among heights and stations more markedly for Atrina sp. than for A. kagoshimensis and R. philippinarum; (2) Atrina sp. always showed higher survival rates at greater heights above the seabed, whereas the other species did not always show this pattern. (3) Survival rates of Atrina sp. showed a different station-to-station variation pattern between experimental runs. (4) In statistical model selection, the spatial variations in the survival rate were not associated for either A. kagoshimensis or R. philippinarum with any of the environmental factors recorded (density of suspended solids, density of chlorophyll $a$, water temperature). In contrast, for Atrina sp. they were strongly and negatively associated with the spatial variations in density of suspended solids.
\end{abstract}

Keywords Survival rate $\cdot$ Spatial variations $\cdot$ Bivalves $\cdot$ Suspended solids

\section{Introduction}

Abundances of wild populations of many bivalves have decreased worldwide in recent years (Gosling 2015). This is also true for commercially important species in the Sea of Ariake, one of the largest basins in Japan. In this basin, the abundances and fishery catches of the ark shell Anadara kagoshimensis (Tokunaga, 1906), the clam Ruditapes philippinarum (Adams \& Reeve, 1850), and the pen shell Atrina sp. decreased from 1970-1980s to 2000-2010s (Kumamoto Prefectural Fisheries Research Center 2006; Yoshino et al. 2007;

Electronic supplementary material The online version of this article (https://doi.org/10.1007/s40071-018-0212-7) contains supplementary material, which is available to authorized users.

T. Kurihara $(\bowtie) \cdot$ K. Hashimoto $\cdot$ S. Nakano · Y. Matsuyama $\cdot$ K. Okamura

Seikai National Fisheries Research Institute, Japan Fisheries Research and Education Agency, 1551-8 Tairamachi,

Nagasaki 851-2213, Japan

e-mail: takeo@affrc.go.jp

A. Ito $\cdot$ M. Kanematsu

National Research Institute of Fisheries and Environment of Inland Sea, Japan Fisheries Research and Education Agency,

1760 Momoshima, Onomichi, Hiroshima 722-0061, Japan 
Koga and Aramaki 2013; Ito 2017; Ministry of the Environment 2017; see "Materials and methods" for the taxonomic problems with Atrina sp.).

To restore these bivalve resources, it is necessary to elucidate how and why their densities vary spatially and temporally. The abundance of marine animals is in general strongly affected by the survival rate during their juvenile stage (e.g., Begon et al. 2006; Broitman et al. 2008; Haddon 2011). Indeed, this relationship is presented for A. kagoshimensis (Masaki and Onohara 2009), R. philippinarum (Nasu et al. 2008), and Atrina sp. (Ito 2017). Therefore, it is important to know how and why the juveniles of A. kagoshimensis, $R$. philippinarum and Atrina sp. change the survival rates.

The survival rates of juveniles of these bivalves in the Sea of Ariake are likely to vary horizontally (i.e., among sea areas) and vertically (i.e., between the seabed and water column). That is, juvenile A. kagoshimensis are likely to survive somewhat better near the mouth of the bay than in the inner area of the bay (Nakamuta et al. 2013) and in the water column compared to the seabed since the juveniles on spat collectors in the water column seem to survive better than the juveniles dropped from the collectors onto the seabed (Masaki and Onohara 2009). Juvenile $R$. philippinarum are likely to survive better in areas with coarser sediments (Kanzaki et al. 2017) and at the higher position on spat collectors (Nagamoto et al. 2017). Juvenile Atrina sp. were found to survive better in the east peripheral area (Suzuki et al. 2009) and in the water column than on the seabed (Matoba et al. 2016).

The patterns and causes for such variations in survival rates in the Sea of Ariake have, however, been studied using different methods among species and among study sites. For example, spat collectors were used in some surveys for A. kagoshimensis (Masaki and Onohara 2009) and R. philippinarum (Nagamoto et al. 2017) but not in any surveys reported for Atrina sp. (Matoba et al. 2016 and references therein); and Atrina sp. were kept in pocket nets in the water column and under fishery nets on the seabed (Matoba et al. 2016). As a result, it is difficult to determine whether the differences in survival rates are due to differences in methods or species-specific and/or site-specific characteristics. How and why the survival rates of each bivalve species horizontally and vertically vary in the Sea of Ariake should be studied to find locations suitable for culture and transplantation of the species, which have been sought by trial and error (Matoba et al. 2016; Nagamoto et al. 2017), and to elucidate what environmental factors are specific to such locations.

We conducted an in situ rearing experiment in the inner area of the Sea of Ariake, using a unified method to examine three problems: (1) how the survival rates of juvenile A. kagoshimensis, R. philippinarum and Atrina sp. vary among stations; (2) how the survival rates vary between the water column and the seabed; and (3) how the horizontal and vertical variations in the survival rates are correlated with turbidity, chlorophyll $a$ concentration, and water temperature. These environmental factors have been found to correlate with the survival rates of many bivalve species (Gosling 2015). High turbidity is suggested to lead to the mortality of Atrina sp. in the Sea of Ariake (Matsuyama 2012; Ministry of the Environment 2017).

\section{Materials and methods}

The study site, the inner area of the Sea of Ariake, is characterized by the great tidal range (about $3.2 \mathrm{~m}$ on average; Matsukawa 2005). This causes strong tidal currents, which leads to cyclic suspension and deposition of sediments $(\operatorname{Md} \varphi=2-8)$. The water temperature and salinity at $5 \mathrm{~m}$ depth are $9{ }^{\circ} \mathrm{C}$ and $30{ }^{\circ} \mathrm{C}$, respectively, in winter and $26^{\circ} \mathrm{C}$ and $27{ }^{\circ} \mathrm{C}$, respectively, in summer.

Three runs of the field experiment of the design in Table 1 were conducted in 2015. The ark shells Anadara kagoshimensis used in each run were wild specimens with shell length 14.5-27.8 mm collected in the Sea of Ariake. The clam Ruditapes philippinarum and pen shell Atrina sp. used were artificially produced seeds with shell length 12.6-14.7 $\mathrm{mm}$ and $8.8-37.9 \mathrm{~mm}$, respectively. These specimens are regarded as juveniles, not sexually matured (Online Resource 1). How the differences in the source and body size of materials potentially affected species-specific results are examined in "Discussion".

The pen shells used were identified as "Atrina pectinata Lineage 2" (sensu Liu et al. 2011) by the analyses of the mtDNA COI region (Hashimoto et al. 2018). Their orthodox species name is, however, unclear owing to the taxonomic confusion of Atrina (Lemer et al. 2014). Therefore, we provisionally call the pen shells "Atrina sp". 
Table 1 Design of each run of the rearing experiment

\begin{tabular}{|c|c|c|c|c|}
\hline & & Run 1 & Run 2 & Run 3 \\
\hline \multirow{3}{*}{$\begin{array}{l}\text { The number of } \\
\text { specimens } \\
\text { used }\end{array}$} & $\begin{array}{l}\text { Anadara } \\
\quad \text { kagoshimensis }\end{array}$ & 5 & 3 & 10 \\
\hline & $\begin{array}{l}\text { Ruditapes } \\
\text { philippinarum }\end{array}$ & 5 & 3 & 10 \\
\hline & Atrina sp. & 3 & 3 & 20 \\
\hline \multirow[t]{3}{*}{$\begin{array}{l}\text { Shell length } \\
\quad(\mathrm{mm})\end{array}$} & $\begin{array}{l}\text { Anadara } \\
\quad \text { kagoshimensis }\end{array}$ & $27.8 \pm 2.5$ & $27.5 \pm 2.4$ & $14.5 \pm 1.5$ \\
\hline & $\begin{array}{l}\text { Ruditapes } \\
\quad \text { philippinarum }\end{array}$ & $14.7 \pm 0.7$ & $14.5 \pm 0.7$ & $12.6 \pm 1.1$ \\
\hline & Atrina sp. & $37.9 \pm 4.0$ & $25.3 \pm 2.8$ & $8.8 \pm 0.7$ \\
\hline \multirow[t]{3}{*}{$\begin{array}{l}\text { Preparation of } \\
\text { bivalve } \\
\text { specimens }\end{array}$} & $\begin{array}{l}\text { Anadara } \\
\quad \text { kagoshimensis }\end{array}$ & $\begin{array}{l}\text { Collected at Kashima }\left(33.07^{\circ} \mathrm{N} \text {, }\right. \\
\left.130.19^{\circ} \mathrm{E}\right) \text {, the inner area of } \\
\text { the Sea of Ariake in } \\
\text { November } 2014\end{array}$ & $\begin{array}{l}\text { Collected at Kashima } \\
\left(33.07^{\circ} \mathrm{N}, 130.19^{\circ} \mathrm{E}\right) \text {, the } \\
\text { inner area of the Sea of } \\
\text { Ariake in November } \\
2014\end{array}$ & $\begin{array}{l}\text { Collected at Ooura } \\
\left(32.94^{\circ} \mathrm{N}, 130.23^{\circ} \mathrm{E}\right), \\
\text { the inner area of the Sea } \\
\text { of Ariake in September } \\
2015\end{array}$ \\
\hline & $\begin{array}{l}\text { Ruditapes } \\
\text { philippinarum }\end{array}$ & $\begin{array}{l}\text { Artificially hatched from adult } \\
\text { clams in November } 2014\end{array}$ & $\begin{array}{l}\text { Artificially hatched from } \\
\text { adult clams in November } \\
2014\end{array}$ & $\begin{array}{l}\text { Artificially hatched from } \\
\text { adult clams in May } 2015\end{array}$ \\
\hline & Atrina sp. & $\begin{array}{l}\text { Artificially hatched from adult } \\
\text { pen shells in July } 2014\end{array}$ & $\begin{array}{l}\text { Artificially hatched from } \\
\text { adult pen shells in July } \\
2014\end{array}$ & $\begin{array}{l}\text { Artificially hatched from } \\
\text { adult pen shells in July } \\
2015\end{array}$ \\
\hline $\begin{array}{l}\text { Experimental } \\
\text { stations }\end{array}$ & & $\mathrm{B}, \mathrm{F}$ & $\mathrm{B}$ & $\mathrm{A}, \mathrm{B}, \mathrm{C}, \mathrm{D}, \mathrm{E}, \mathrm{F}$ \\
\hline $\begin{array}{l}\text { Heights of } \\
\text { trays from } \\
\text { the seabed } \\
(\mathrm{cm})\end{array}$ & & 0,40 & $0,20,40$ & 0,20 \\
\hline $\begin{array}{l}\text { The number of } \\
\text { trays for } \\
\text { each station } \\
\text { and height }\end{array}$ & & 1 & 2 & 2 \\
\hline $\begin{array}{l}\text { Start of the } \\
\text { experiment }\end{array}$ & & 27 May & 5 September & 7 October \\
\hline $\begin{array}{l}\text { Experimental } \\
\text { period (days) }\end{array}$ & & 15 & 16 & 16 \\
\hline
\end{tabular}

Experimental design differed among the three runs, depending on the availability of bivalves. Each run was conducted at some or all of the stations A to F in Fig. 1. The design of Run 1 was: two stations (B and F; Fig. 1) $\times$ two heights from the seabed $(0$ and $40 \mathrm{~cm}) \times$ one rearing tray. Four trays were used in total. The trays were made of polypropylene with $35 \mathrm{~cm}$ width, $24 \mathrm{~cm}$ length, and $7 \mathrm{~cm}$ height. In each tray, anthracite (i.e., hard, compact coal) with a diameter of about $2 \mathrm{~mm}$ was filled to $5 \mathrm{~cm}$ height. Height of a tray was defined as the distance from the upper face of anthracite in the tray to the seabed. The heights of trays from the seabed was set $<1 \mathrm{~m}$ in each run, which is based on previous reports for A. kagoshimensis and Atrina sp. in the Sea of Ariake that survival rates sharply varied between specimens reared on the seabed and reared in the water column $<1 \mathrm{~m}$ distant from the seabed (Yurimoto et al. 2007; Matoba et al. 2016). Five A. kagoshimensis, five $R$. philippinarum and three Atrina sp. were embedded into the anthracite of each tray on 24 May. The trays were covered with a $2 \mathrm{~mm} \times 2 \mathrm{~mm}$ mesh and were maintained in a bath with flowing seawater. The trays were then set at each height and station by divers on 27 May, using steel frames and stakes. They were recovered 15 days later to record the survival/death of each specimen.

The design of Run 2 was: one station (B in Fig. 1) $\times$ three heights from the seabed $(0,20$ and $40 \mathrm{~cm}) \times$ two trays. Six trays were used in total. Three specimens of each species were embedded into 


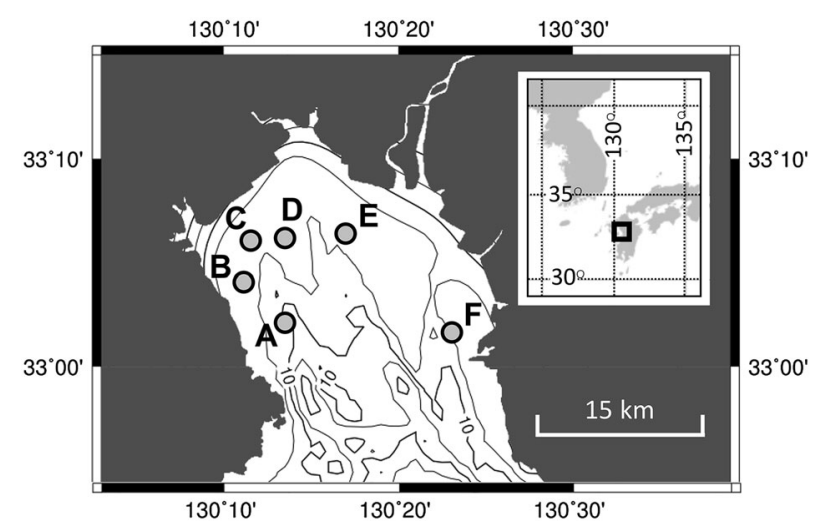

Fig. 1 Location of the study site, the inner part of the Sea of Ariake (rectangular area in a smaller map) and the experimental stations (gray circles in a larger map). The correspondence of these stations between the present and previous studies (e.g., Ministry of Agriculture, Forestry and Fisheries 2011) is as follows: "A" = "P6", "B" = "T14", "C" = "15", "D" = "O-5a", "E" = "SU-H", "F" = "T5"

anthracite in each tray on 5 September using the same method as in Run 1. The trays were set at the station on 7 September and were recovered 16 days later.

The design of Run 3 was: six stations (A to $\mathrm{F}$ in Fig. 1$) \times$ two heights from the seabed $(0$ and $20 \mathrm{~cm}) \times$ two trays. In total, 24 trays were used. Ten A. kagoshimensis, 10 R. philippinarum and 20 Atrina sp. were embedded into anthracite in each tray on 5 October using the same method as in Run 1 . The trays were set at the six stations on 7 October and were recovered 16 days later. Environmental factors were measured for only Run 3. Turbidity (FTU), chlorophyll fluorescence intensity, and temperature $\left({ }^{\circ} \mathrm{C}\right)$ were measured for each station and height with an interval of 10 min throughout the run, using a data logger CLW-U (JFE Advantech Co., Ltd, http://ocean.jfe-advantech.co.jp/english/index.html). The records of turbidity and chlorophyll fluorescence intensity were converted to density of suspended solids (SS; mg/l) and chlorophyll $a$ density (Chl- $a$; $\mu \mathrm{g} / \mathrm{l}$ ) with transformation formulae (Online Resource 2) that had been constructed before the experiments.

The data of each run were used to examine the horizontal and vertical variations in bivalve survival rates (except for Run 2, which lacked replications of stations and thus cannot be used to examine the horizontal variation in survival rates). The data of Run 3 were also used to examine how SS, Chl- $a$ and water temperature spatially vary. Median of each environmental factor during Run 3 was compared between heights and among stations with a Friedman test. In addition, the data of Run 3 were used to analyze survival rates of each species with a generalized linear model with mixed effects (GLMM) based on a logit function and binomial distribution. The objective variable was survival rate for each tray. The explanatory variables were median SS, median Chl- $a$, median water temperature, height above the seabed, and station for each tray. The random factor was associated with the difference in uninvestigated factors (e.g., microenvironment) between two trays within each combination of height and station. The best combination of explanatory factors was selected with the Bayesian information criterion (BIC). The calculation was performed with R (R Core Team 2017) and the package, glmmML, ver. 1.0.2 (Broström 2017). Although the shell length of each species somewhat varied among experimental trays owing to random allocation, its effect on the tray-to-tray variation in survival rate was negligible (Pearson's correlation coefficient $r=-0.14$ and $p=0.52$ for A. kagoshimensis; -0.23 and 0.27 for $R$. philippinarum; 0.013 and 0.95 for Atrina sp).

\section{Results}

The horizontal variations in survival rate in Runs 1 and 3 (Figs. 2 and 3) were small for Anadara kagoshimensis, as its median survival rates were always 1.0 except for $0 \mathrm{~cm}$ height at stations $\mathrm{D}(0.90)$ and $\mathrm{F}(0.70)$ in Run 3. The variations were also small for Ruditapes philippinarum, as its survival rates were always 1.0 in Run 1 and were generally high (0.69-1.0) in Run 3 except for $0 \mathrm{~cm}$ height at station $\mathrm{F}(0.58)$. Compared to these two species, the horizontal variations in survival rate were greater for Atrina sp. Its survival rates were 


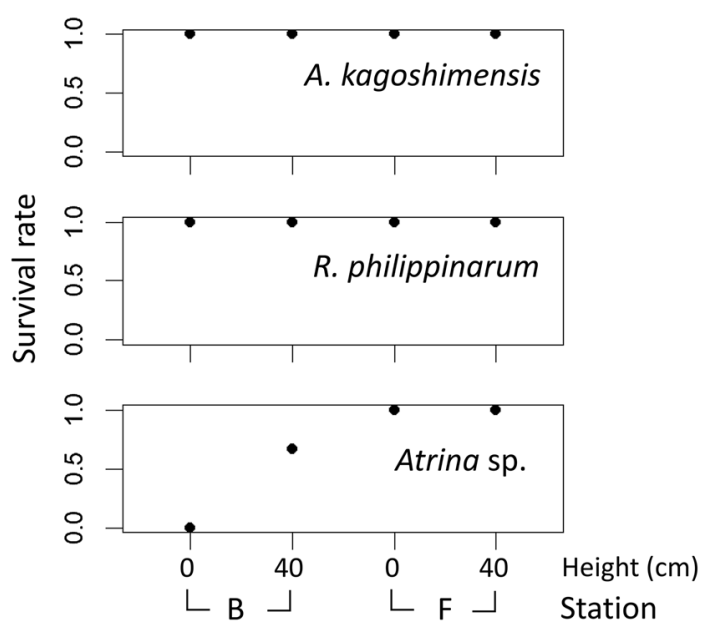

Fig. 2 Survival rates of Anadara kagoshimensis, Ruditapes philippinarum, and Atrina sp. for each combination of station and height in Run 1 of the rearing experiments

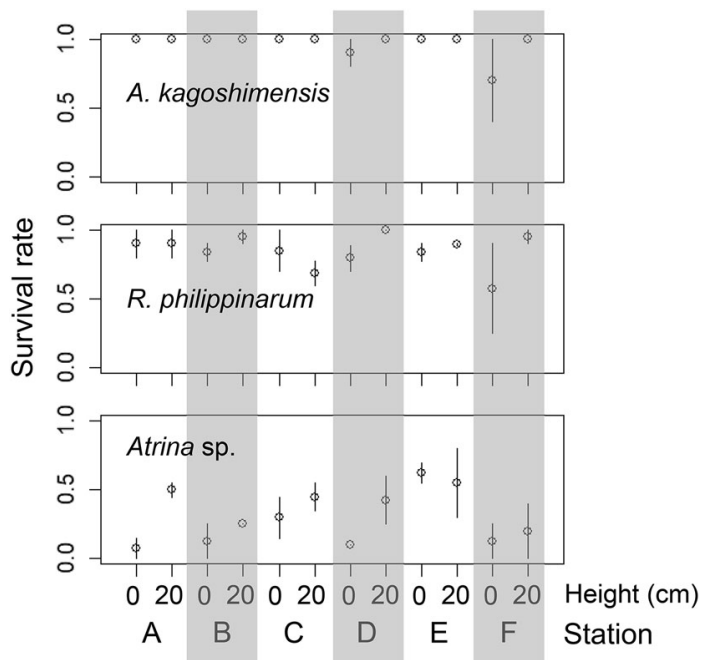

Fig. 3 Survival rates of Anadara kagoshimensis, Ruditapes philippinarum, and Atrina sp. for each combination of station and height in Run 3 of the rearing experiments. Circles denote median survival rates, and bars the range

much higher for station F (1.0) than station B (0.0-0.67) in Run 1, and for station E (0.55-0.63) than stations F and B (0.13-0.25) in Run 3.

Survival rates of A. kagoshimensis showed unclear vertical changes. The values were slightly higher for $20 \mathrm{~cm}$ height than $0 \mathrm{~cm}$ height in Run 2 (Fig. 4) and in Run 3 (stations D and F; Fig. 3), and the rates were the same between the heights in Run 1 (1.0; Fig. 2). Survival rates of $R$. philippinarum showed variable vertical changes. The rates were the same between the heights in Run 1 (1.0); higher for $0 \mathrm{~cm}$ height (1.0) than $20 \mathrm{~cm}$ height (0.83) in Run 2; and showed different vertical-variation patterns in Run 3, depending on the station (20 cm height $>0 \mathrm{~cm}$ height at stations B, D, E and F; $20 \mathrm{~cm}<0 \mathrm{~cm}$ at station C; $20 \mathrm{~cm}=0 \mathrm{~cm}$ at station A). In contrast to A. kagoshimensis and R. philippinarum, Atrina sp. showed lower survival rates nearer and on the seabed in general: at station B in Runs 1 and 2; and at most stations (stations A, B, C, D and F) in Run 3.

Figure 5 shows the horizontal and vertical variations in medians of SS, Chl- $a$, and water temperature in Run 3. Median SS was lower at stations A ( 25.2 and $16.5 \mathrm{mg} / \mathrm{L}$ for 0 and $20 \mathrm{~cm}$ heights, respectively) and E (20.5 and $19.3 \mathrm{mg} / \mathrm{L}$ ) than the other stations $(>45.8$ and $>31.2 \mathrm{mg} / \mathrm{L}$ ) for each height; and $0 \mathrm{~cm}$ height $(30.7-261.5 \mathrm{mg} / \mathrm{L})$ than $20 \mathrm{~cm}$ height (32.5-125.6) for most stations. Median Chl- $a$ was also lower at station A $(5.4$ and $5.0 \mu \mathrm{g} / \mathrm{L}$ for 0 and $20 \mathrm{~cm}$ heights, respectively) and E (2.4 and $2.2 \mu \mathrm{g} / \mathrm{L})$ than the other stations 


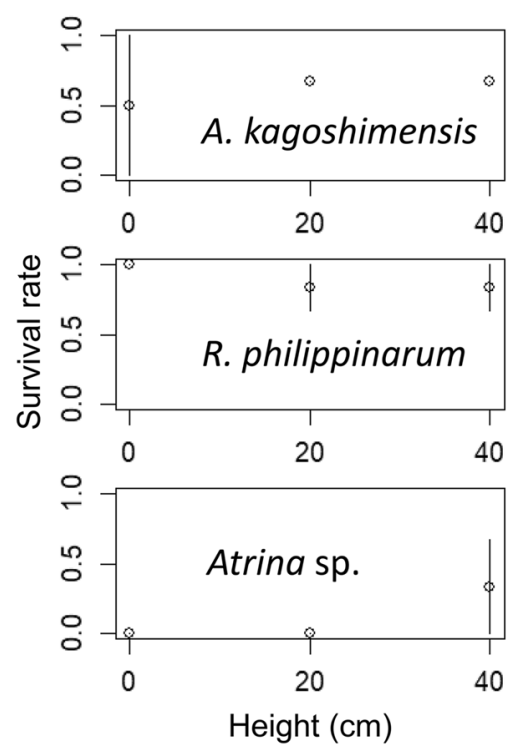

Fig. 4 Survival rates of Anadara kagoshimensis, Ruditapes philippinarum, and Atrina sp. in Run 2 of rearing experiments conducted at station B. Circles denote median survival rates, and bars the range

$(>8.9$ and $>10.1 \mu \mathrm{g} / \mathrm{L})$ for each layer, but less varied between layers $(2.4-17.2 \mu \mathrm{g} / \mathrm{L}$ for $0 \mathrm{~cm}$ height and $2.2-14.5 \mu \mathrm{g} / \mathrm{L}$ for $20 \mathrm{~cm}$ height). Median water temperature was higher at stations A and F (>22 $\left.{ }^{\circ} \mathrm{C}\right)$ than the other stations $\left(<22{ }^{\circ} \mathrm{C}\right)$ and was nearly the same between heights. These spatial variations in environmental factors showed non-significant, but low, significance probabilities $\left(p=0.103-0.157\right.$ and $\chi^{2}=2.00-2.67$ for vertical variations; $p=0.0752-0.210$ and $\chi^{2}=7.14-10.00$ for horizontal variations; Friedman test). The spatial variations were correlated significantly between Chl- $a$ and SS (Spearman rank correlation $\rho=0.713$, $p=0.0276$ corrected with Holm's method) and between Chl- $a$ and water temperature $(\rho=-0.768$, $p=0.0107)$ but not significantly between SS and water temperature $(\rho=-0.4965, p=0.302)$.

Of these spatial variations in environmental factors, the variations in median SS corresponded with the variations in Atrina sp. survival rate in that median SS was relatively low for the stations and height with the survival rates being relatively high (i.e., station $\mathrm{E}$ and $20 \mathrm{~cm}$ height). Atrina sp. survival rate was $0.45-0.55$ for the lowest, median SS (16.5 mg/L), whereas it decreased to $0.00-0.25$ for the highest, median SS $(80.2 \mathrm{mg} / \mathrm{L})$. Such a correspondence led to the selected statistical model that explains the variation in Atrina sp. survival rate with the variation in only SS (McFadden's pseudo $R^{2}$ for $\mathrm{SS}=0.084$; see Table 2 for the selected model and Online Resource 3 for every model examined). In contrast with Atrina sp., the other two species did not show a clear correspondence between their survival rates and environmental factors. This led to the selected statistical model that explains the variation in $R$. philippinarum survival rate with no environmental factors (Table 2 and Online Resource 4). GLMM did not converge for A. kagoshimensis. These species-specific correspondences between survival rate and SS are mirrored in Fig. 6 in that only Atrina sp. showed a sharp decrease in survival rate against SS.

\section{Discussion}

Although experimental design and replication differed among the three experimental runs, the patterns of horizontal and vertical variations in survival rates were similar among the runs in that the variations were great for only Atrina sp. in survival rates, as follows. Only Atrina sp. showed marked differences in survival rate among the experimental stations. In Run 1, Atrina sp. survived better at station F than station B. This concurs with Suzuki et al. (2009), who indicated relatively high survival rates of juvenile Atrina sp. in the east, inner area of the Sea of Ariake (including station F), based on their finding that the ratio of spat density to larval density was higher for the east sea area than a west inner sea area. In Run 3, however, juvenile Atrina sp. survived slightly better at station E than the other stations including station F. Hence, it is possible that the 

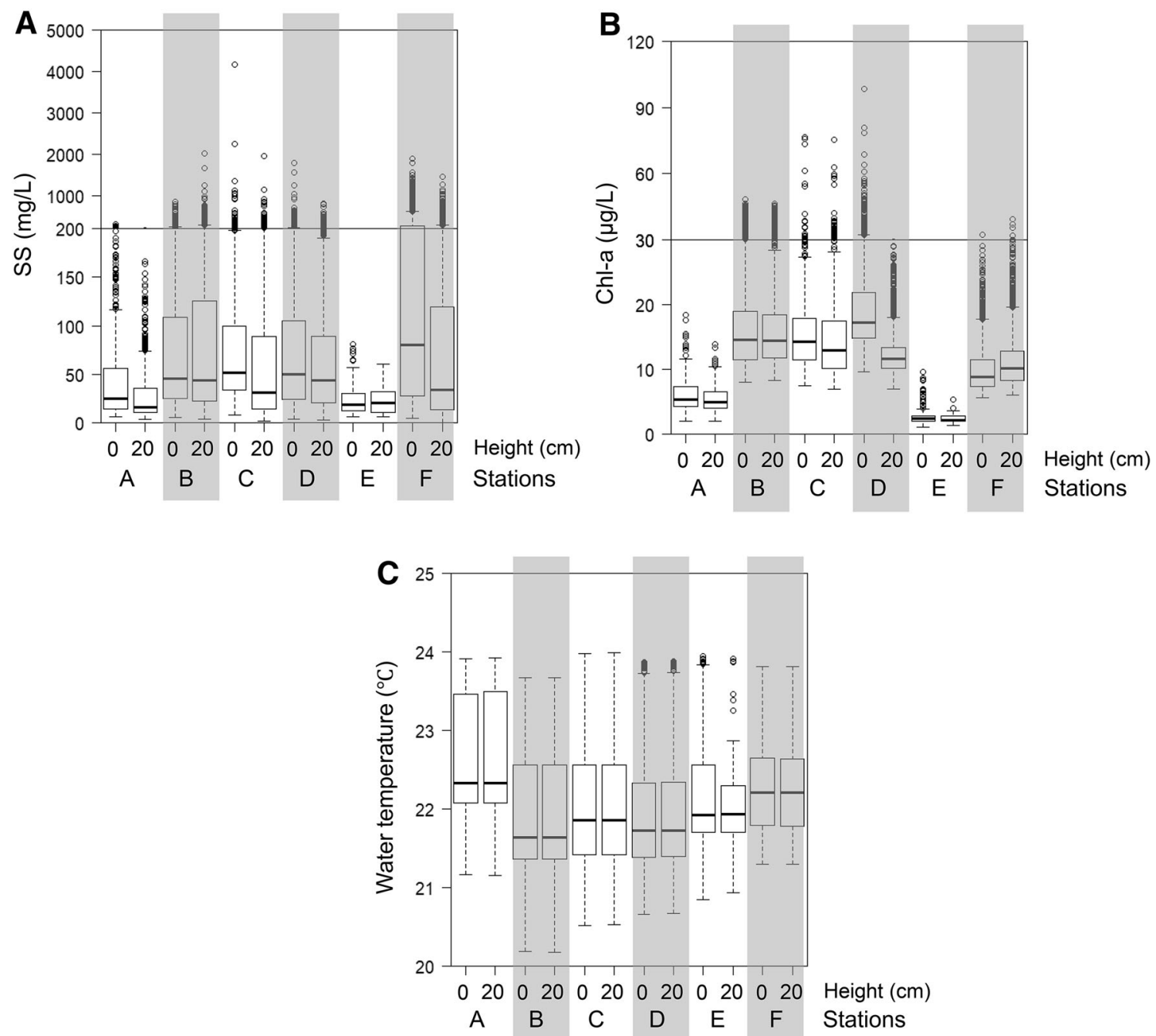

Fig. 5 Environmental factors in Run 3. a Suspended solids (SS, mg/L), b chlorophyll $a$ concentration $(\mu \mathrm{g} / \mathrm{L})$, and $\mathbf{c}$ water temperature $\left({ }^{\circ} \mathrm{C}\right)$. Suspended solids occasionally showed extremely high values and thus are displayed separately for $0-200 \mathrm{mg} / \mathrm{L}$ and $200-5000 \mathrm{mg} / \mathrm{L}$ at different scales. Likewise, chlorophyll $a$ concentration is displayed separately for $0-30 \mu \mathrm{g} / \mathrm{L}$ and $30-120 \mu \mathrm{g} / \mathrm{L}$

Table 2 Models showing the lowest BIC for (a) Atrina sp. and (b) Ruditapes philippinarum

\begin{tabular}{llr}
\hline Species & Model & BIC \\
\hline Atrina sp. & $p=1 /(1+\exp (-0.44 \pm 0.61+(0.039 \pm 0.015) \mathrm{SS}))$ & 75.91 \\
R. philippinarum & $p=1 /(1+\exp (-1.96 \pm 0.30))$ & 45.83
\end{tabular}

The estimates of parameters are presented as the most likely value \pm standard error. See Online Resources 2 and 3 for more details of the results of the model selection

" $p$ " denotes expected survival rates, $S S$ the density of suspension solids

locations with Atrina sp. surviving well are variable and are affected by short-term fluctuations in some environmental factors. In addition, Atrina sp. of smaller body sizes was used in Run 3 than Run 1, which might have led to the different patterns in horizontal survival variation. For example, the tidal current is in general faster at station $F$ than station E (Tsukamoto and Yanagi 2002), which possibly was more stressful for small specimens at station $\mathrm{F}$ than station $\mathrm{E}$ and led to the lower survival rates at station $\mathrm{F}$ than station $\mathrm{E}$ in Run 3 . 


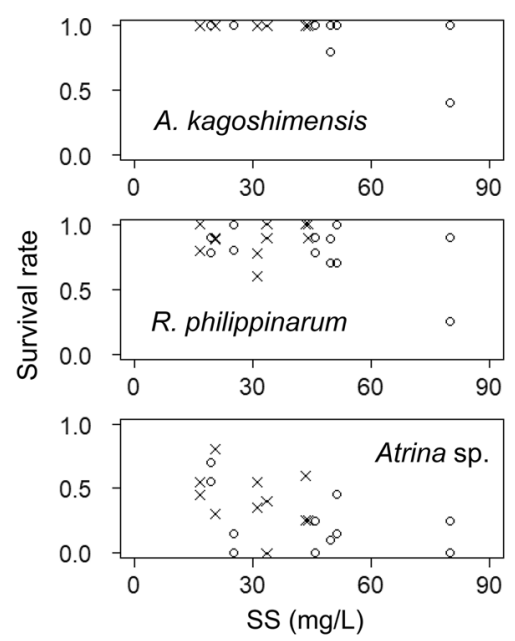

Fig. 6 Survival rates of Anadara kagoshimensis, Ruditapes philippinarum, and Atrina sp. plotted against suspended solids (SS) for each station and height in Run 3 of rearing experiments. Circles denote $0 \mathrm{~cm}$ height, and crosses $20 \mathrm{~cm}$ height

Atrina sp. survived better in trays higher in the water column in all runs, whereas neither Anadara kagoshimensis nor Ruditapes philippinarum showed this pattern. This accords with the previous experiments in the Sea of Ariake for Atrina sp. and A. kagoshimensis at least. Atrina sp. with shell length $7 \mathrm{~cm}$ showed higher survival rates $(>60 \%)$ about $1 \mathrm{~m}$ above the seabed than on the seabed $(<20 \%)$ during MarchDecember 2015 (Matoba et al. 2016). In contrast to Atrina sp., A. kagoshimensis with shell length 3-4 cm showed similar survival rates, about $80 \%, 1 \mathrm{~m}$ above the seabed and on the seabed during February-October 2003 (Yurimoto et al. 2007). No such experiment comparing water column and sea bed has been reported for $R$. philippinarum in the Sea of Ariake to our knowledge. Although wild A. kagoshimensis and artificially produced Atrina sp. were used in our experiments, the difference between wild specimens and artificially hatched seeds is unlikely to result in the overestimation of the difference in survival rate between $A$. kagoshimensis and Atrina sp. This is because the survival rates of wild A. kagoshimensis are reported to be similar (Katayama et al. 1982) or lower (Takami and Yoshioka 1982, 1983), compared to those of artificially produced A. kagoshimensis in transplantation experiments. Therefore, if we had used artificially produced seeds for A. kagoshimensis as well as for Atrina sp., the difference in survival rates is expected to be either unchanged or larger.

In previous experiments rearing A. kagoshimensis and Atrina sp. near the seabed and in the water column in the Sea of Ariake, techniques for keeping bivalves differed between water column and seabed: pocket net and flat fishing net, respectively, for Atrina sp. (Matoba et al. 2016); and pocket net and resin-made basket, respectively, for A. kagoshimensis (Yurimoto et al. 2007). Our experiments showed that, regardless of such depth-dependent differences in equipment, Atrina sp. has higher survival rates when maintained in the water column than on the seabed, while A. kagoshimensis does not. Hence, the environmental factors show that Atrina sp. experience is likely to be less favorable near the seabed than in the water column.

One of the adverse environmental factors that Atrina sp. experience in some sea areas and near the seabed can be suspended solids. This is indicated from the result of model selection in Run 3, where the best model included the term SS and excluded the terms stations and height. Adverse effects of suspended solids are reported for many bivalve species (e.g., Bricelj et al. 1984; Navarro et al. 1992; Navarro and Widdows 1997) including the conspecific species Atrina zelandica (Ellis et al. 2002). A. zelandica showed a decrease in glycogen content and relative weight of soft tissue in the survey areas with abundant suspended solids. Suspended solids would adversely affect Atrina sp. through various pathways. Increased suspended solids can lead to decrease in clearance rate of particulates and filtration rate of water (e.g., Navarro et al. 1992; Navarro and Widdows 1997; Ellis et al. 2002), thereby causing decreased amount of food and oxygen acquired. Suspended solids can also lead to increased ejection of pseudofeces, thereby causing increased energy consumption (Madon et al. 1998). Such adverse effects would further increase, if suspended solids accumulate on the seabed and lead to an increased density of the suspended solids near the inhalant openings of Atrina sp. 
Yurimoto et al. (2008) found that the glycogen content in its adductor muscle, an index of the condition, decreased in relation to the thickness of a high-density layer of suspended solids in a rearing experiment. Accumulation of suspended solids was found on the surface of the substrate used in our experimental trays (Kurihara, personal observation), which possibly increased the adverse effects of the solids for Atrina sp.

Why, of the three experimental species, only Atrina sp. showed clear negative correlations between its survival rate and the density of suspended solids might be related with endurance to hypoxia. Atrina $\mathrm{sp}$. is more vulnerable to hypoxia than A. kagoshimensis and R. philippinarum: median lethal time, LT50, with dissolved oxygen $<0.4 \mathrm{mg} / \mathrm{L}$ is reported to be $<9 \mathrm{~h}$ for Atrina sp. (mean shell length $23 \mathrm{~mm}$; Nagasoe et al. 2017), which is far shorter than $130 \mathrm{~h}$ for A. kagoshimensis $(28 \mathrm{~mm}$; estimated from the Fig. 1 of Miyamoto and Iwanaga 2012) and $70 \mathrm{~h}$ for R. philippinarum (31 mm; Yamada et al. 2016). Thus, if higher SS causes lower filtration rate (Navarro and Widdows 1997), thereby causing lower uptake of oxygen, Atrina sp. would suffer more greatly than A. kagoshimensis and R. philippinarum.

Future studies should examine how the patterns of spatial change in survival rate are affected by the body size and density of bivalves. It is likely that, for the bivalve species in the present study, smaller specimens are more vulnerable to various environmental stresses. This is reported for $R$. philippinarum exposed to physical disturbances due to typhoon (Mizuta et al. 2011) and for Atrina sp. exposed to hyposaline stress (Yamamoto and Handa 2011; Kurihara et al. 2017) and hypoxia (Nagasoe et al. 2017). Therefore, as we used juveniles for each species, interspecific differences in the responses to spatial variation in environmental factors might have been emphasized. Yet, even if we used larger specimens for each species, Atrina sp. would probably show great spatial variations in survival rates. This is suggested by Matoba et al. (2016) and Yoshida et al. (2007) who showed that large Atrina sp. (shell length $>200 \mathrm{~mm}$ in Matoba et al. 2016 and about $100 \mathrm{~mm}$ in Yoshida et al. 2007) survived better in pocket nets in the water column (90\% per 10 months) than in cages on the seabed (20\% per 10 months); and on the tidal flats (20-30\% per 10 months) than in the subtidal area (0\% per $<10$ months). The densities of A. kagoshimensis and Atrina sp. in our experimental trays (35.7-119 $\mathrm{m}^{-2}$ and 35.7-238 $\mathrm{m}^{-2}$, respectively) were higher than those in their natural habitats $\left(<50 \mathrm{~m}^{-2}\right.$ and $<80 \mathrm{~m}^{-2}$, respectively; Yoshino et al. 2007; Suzuki et al. 2009). Whether the present experimental results for such high densities differ from the results for natural, low densities should be examined in future.

We found that survival rates were lower for Atrina sp. than for A. kagoshimensis and R. philippinarum on the seabed in the inner area of the Sea of Ariake. This suggests that the environmental factors are especially unfavorable for Atrina sp. at present. This notion is in accordance with the abundance and the status of fisheries for the three species in the inner area of the Sea of Ariake in recent years. The density of $A$. kagoshimensis averages about $100 \mathrm{~m}^{-2}$ in the intertidal area (Nakamuta et al. 2013) and $200 \mathrm{~m}^{-2}$ in the subtidal area (Okamura, personal data for 2015). The density of $R$. philippinarum attains $1000-5000 \mathrm{~m}^{-2}$ in the intertidal area (Kanzaki et al. 2017; no information for the subtidal area). These two species are still harvested by fishermen (Ministry of the Environment 2017). In contrast, the densities of juvenile Atrina sp. have been $<1 \mathrm{~m}^{-2}$ in most of the subtidal area of the inner part of the Sea of Ariake between 1997 and 2011 (Koga and Aramaki 2013). It has been legally prohibited to catch Atrina sp. therein since 2012 owing to the low abundance (Ito 2017). It is necessary to investigate the environmental factors especially unfavorable for Atrina sp.

Acknowledgements We thank Junichi Uchikawa (Kumamoto Prefectural Fisheries Research Center) for providing the bivalve samples. We thank Kengo Suzuki (Hokkaido National Fisheries Research Institute) for commenting on the present study. We thank Nishimura Syokai Co., Ltd., Japan Justice Co., Ltd., and Minefuku Kaiji for their support in our field experiments. The present study was made as a part of contract work with Ministry of the Environment, Japan.

Open Access This article is distributed under the terms of the Creative Commons Attribution 4.0 International License (http:// creativecommons.org/licenses/by/4.0/), which permits unrestricted use, distribution, and reproduction in any medium, provided you give appropriate credit to the original author(s) and the source, provide a link to the Creative Commons license, and indicate if changes were made. 


\section{References}

Begon M, Townsend CR, Harper JL (2006) Ecology: From Individuals To Ecosystems, 2nd edn. Blackwell, Malden, p 738

Bricelj VM, Malouf RE, Quillfeldt C (1984) Growth of juvenile Mercenaria mercenaria and the effect of resuspended bottom sediments. Mar Biol 84:167-173

Broitman BR, Blanchette CA, Menge BA, Lubchenco J, Krenz C, Foley M, Raimondi PT, Lohse D, Gaines SD (2008) Spatial and temporal patterns of invertebrate recruitment along the west coast of the United States. Ecol Monogr 78:403-421

Broström G (2017) Generalized linear models with clustering. https://cran.r-project.org/web/packages/glmmML/glmmML.pdf. Accessed 4 Feb 2018

Ellis J, Cummings V, Hewitt J, Thrush S, Norkko A (2002) Determining effects of suspended sediment on condition of a suspension feeding bivalve (Atrina zelandica): results of a survey, a laboratory experiment and a field transplant experiment. J Exp Mar Biol Ecol 267:147-174

Gosling E (2015) Marine Bivalve Molluscs, 2nd edition. NY: John Wiley \& Sons, Ltd. 524 pages

Haddon M (2011) Modelling and quantitative methods in fisheries, 2nd edn. Taylor \& Francis Group, New York

Hashimoto K, Yamada K, Nagae A, Matsuyama Y (2018) Lineage specific detection of the scaly form of the pen shell Atrina spp. by a loop-mediated isothermal amplification method. Fish Sci. https://doi.org/10.1007/s12562-018-1231-4

Ito S (2017) Reviving the pen shell, Atrina spp. diving apparatus fishery in the inner part of Ariake Sound. Bull Saga Pref Ariake Fish Res Develop Cent 28:147-166 (in Japanese with English abstract)

Kanzaki H, Tsukuda M, Tsujo K (2017) Distribution of Manila clam, Ruditapes philippinarum, on the tidal flat at the mouths of Tara and Itoki Rivers in Ariake Sound. Bull Saga Pref Ariake Fish Res Develop Cent 28:119-123 (in Japanese)

Katayama S, Miyake Y, Ikegami T, Ikeda Z (1982) Experiments on aquaculture of Anadara kagoshimensis in Okayama Prefecture, Japan. In: Nansei National Fisheries Research Institute (eds) Rearing experiments for causes of high mortality of Anadara kagoshimensis. Volume I. Hiroshima, p 2-15 (in Japanese)

Koga H, Aramaki H (2013) History of the pen shell, Atrina spp. fishery and the factors relevant to the fishing ground formation in Saga Ariake Bay-especially, some consideration about the factors of big catch in 2009 fiscal fishing period. Bull Saga Pref Ariake Fish Res Develop Cent 26:13-24 (in Japanese with English abstract)

Kumamoto Prefectural Fisheries Research Center (2006) Guidance for resource management of the Asari clam Ruditapes philippinarum in Kumamoto Prefecture, version II. https://www.pref.kumamoto.jp/common/UploadFileOutput.ashx?c_id= 3\&id=9666\&sub_id=1\&flid=13700.Accessed 24 Nov 2018 (in Japanese)

Kurihara T, Nakano S, Matsuyama Y, Hashimoto K, Yamada K, Ito A, Kanematsu M (2017) Survival time of juvenile pen shell Atrina pectinata (Bivalvia: Pinnidae) in hyposaline water. Int Aquat Res. https://doi.org/10.1007/s40071-017-0183-0

Lemer S, Buge B, Bemis A, Giribet G (2014) First molecular phylogeny of the circumtropical bivalve family Pinnidae (Mollusca, Bivalvia): evidence for high levels of cryptic species diversity. Mol Phylogenet Evol 75:11-23. https://doi.org/10.1016/j. ympev.2014.02.008

Liu J, Li Q, Kong LF, Zheng XD (2011) Cryptic diversity in the pen shell Atrina pectinata (Bivalvia: Pinnidae): high divergence and hybridization revealed by molecular and morphological data. Molec Ecol 20:4332-4345

Madon SP, Schneider DW, Stoeckel JA, Sparks RE (1998) Effects of inorganic sediment and food concentrations on energetic processes of the zebra mussel, Dreissena polymorpha: implications for growth in turbid rivers. Can J Fish Aquat Sci $55: 401-413$

Masaki K, Onohara T (2009) Relationship between juvenile ark shell, Scapharca kagoshimensis, development and weather conditions in the inner area of the Ariake Sound. Bull Saga Pref Ariake Fish Res Develop Cent 24:13-18 (in Japanese with English abstract)

Matoba T, Hirose M, Nagamoto A, Yoshida M, Shinohara N (2016) Research on the causes for the mortality of the pen shell Atrina sp. in Fukuoka sea area of the Sea of Ariake, IV. Bull Fukuoka Fish Mar Tech Res Cent 26:1-8 (in Japanese)

Matsukawa Y (2005) Physical process. In: The Oceanographic Society of Japan (ed) Restoration of ecosystem in the Sea of Ariake. Koseisha Koseikaku, Tokyo, pp 3-11 (in Japanese)

Matsuyama Y (2012) Abnormal mortality of the pen shell Atrina spp. and efforts for recovery of the resource. In: Ohshima Y (ed) Current status and issues of the Ariake Bay, a potentially highly productive Coastal Sea. Koseisha Koseikaku, Tokyo, pp 53-62

Ministry of Agriculture, Forestry and Fisheries (2011) Dissolved oxygen. http://www.maff.go.jp/kyusyu/seibibu/isahaya/pdf/011_ 6_2_4_youzonnsannso_1.pdf. Accessed 3 Feb 2018

Ministry of the Environment (2017) Ariakekai Yatsushirokai Sogo Tyosa Hyoka Iinkai Hokokusho. https://www.env.go.jp/ council/20ari-yatsu/rep061221/index.html Accessed 17 April 2018; (in Japanese)

Miyamoto Y, Iwanaga C (2012) Biochemical responses to anoxia and hypoxia in the ark shell Scapharca kagoshimensis. Plankton Benthos Res 7:167-174

Mizuta K, Hirano K, Higano J, Tamaki A (2011) Effects of typhoons on artificially-made culture grounds for the manila clam Ruditapes philippinarum along Konagai coast of Isahaya Bay, Kyushu, Japan. Aquac Sci 59:75-88 (in Japanese with English abstract)

Nagamoto A, Matoba T, Shinohara N (2017) Efficiency of preventive measures against burial of bivalve spat collector using gravel bag in Fukuoka area of the Sea of Ariake, Japan. Bull Fukuoka Fish Mar Tech Res Cent 27:1-8 (in Japanese)

Nagasoe S, Tokunaga T, Matsuyama Y (2017) Effect of hypoxic conditions on the survival of juvenile pen shell Atrina cf. japonica (an East Asian species). Suisan Zosyoku (Aquacult Sci) 65:125-132

Nakamuta H, Fujisaki H, Yoshida K (2013) Abnormal mortality of the ark shell, Scapharca kagoshimensis, occurred from the autumn to winter in 2011. Bull Saga Pref Ariake Fish Res Develop Cent 26:33-48 (in Japanese with English title) 
Nasu H, Ikushima N, Tobase N, Nakahara Y (2008) The present status and a problem of the fishery for the clam Ruditapes philippinarum in Kumamoto Prefecture. Rep Kumamoto Pref Fish Res Cent 8:89-99 (in Japanese with English title)

Navarro JM, Widdows J (1997) Feeding physiology of Cerastoderma edule in response to a wide range of seston concentrations. Mar Ecol Prog Ser 152:175-186

Navarro E, Iglesias JIP, Ortega MM (1992) Natural sediment as a food source for the cockle Cerastoderma edule (1): effect of variable particle concentration on feeding, digestion and the scope for growth. J Exp Mar Biol Ecol 156:69-87

R Core Team (2017) R: A language and environment for statistical computing. R foundation for statistical computing, Vienna, Austria. https://www.R-project.org/. Accessed 16 Dec 2017

Suzuki K, Yurimoto T, Watanabe Y, Koshiishi Y, Kimoto K, Yoshida M, Fujisaki H, Fujii A, Nasu H (2009) Distribution of planktonic larvae and spats of the pen shell Atrina spp. in Ariake Bay, southern Japan for years 2003-2005. Bull Jpn Soc Fish Oceanogr 73:161-171 (in Japanese with English abstract)

Takami T, Yoshioka S (1982) Rearing experiments of Anadara kagoshimensis in Yamaguchi Prefecture. In: Nansei National Fisheries Research Institute (ed) Rearing experiments for causes of high mortality of Anadara kagoshimensis. Volume I. Hiroshima, p 16-28 (in Japanese)

Takami T, Yoshioka S (1983) Rearing experiments of Anadara kagoshimensis in Yamaguchi Prefecture. In: Nansei National Fisheries Research Institute (ed) Rearing experiments for causes of high mortality of Anadara kagoshimensis. Volume II. Hiroshima, p 9-19 (in Japanese)

Tsukamoto H, Yanagi T (2002) Tide and tidal current in Ariake Bay. Umi To Sora 78:31-38 (in Japanese with English abstract)

Yamada K, Miyamoto Y, Nakano T, Okamura K (2016) Inter- and intraspecific variation in anoxic survival among three bivalve species in intertidal and subtidal areas along the coast of Japan. Plankton Benthos Res 11:49-56

Yamamoto K, Handa T (2011) Effect of low salinity in ambient water on ventilation in the pen-shell Atrina (Servatrina) lischkeana. Suisan Zosyoku (Aquacult Sci) 59:535-540 (in Japanese with English abstract)

Yoshida M, Ito T, Chikushi Y (2007) The study of transplantation of the pen-shell (Atrina pectinata japonica). Bull Fukuoka Fish Mar Tech Res Cent 17:1-5 (in Japanese)

Yoshino K, Yamamoto K, Hayami Y, Hamada T, Kasagi T, Ueno D, Ohgushi K (2007) Benthic fauna of the inner part of Ariake Bay: long-term changes in several ecological parameters. Plankton Benthos Res 2:198-212

Yurimoto T, Nasu H, Tobase N, Maeno Y (2007) Growth, survival and feeding of ark shell Scapharca kagoshimensis with hung and settled culture in Ariake Bay, Japan. Suisan Zosyoku (Aquacult Sci) 55:535-540 (in Japanese with English abstract)

Yurimoto T, Tanaka K, Nasu H, Matsuoka K (2008) Influence of resuspended sediments and their surface accumulation on a pen shell Atrina pectinata in Ariake Bay, West Japan. Suisan Zosyoku (Aquacult Sci) 56:335-342 (in Japanese with English abstract)

\section{Publisher's Note}

Springer Nature remains neutral with regard to jurisdictional claims in published maps and institutional affiliations. 